\title{
15 Introduction
}

Part IV looks at stress from a manager's perspective. Line managers have a legal responsibility and a moral obligation to try to spot signs that stress may be affecting any team member's health. They have a vested interest in looking for signs that stress may be affecting performance. As Chapter 16 discusses, the law does not expect managers to be mind readers, but to spot signs of stress that any reasonable person would. Part IV begins with the legal responsibilities of managers because it is often the first topic on the agenda when stress and stress management interventions are discussed within organizations.

Beyond what is explicitly required by the law, there are a number of best practice models that managers should use, which should be adopted by every organization. Chapter 17 discusses four elements of best practice for managers to reduce team stress:

1. Policy and procedure, including:

— stress management, mental health, or well-being policy

- procedure for managing stress-related illness

— procedure for stress-related absence

— individual risk assessment

- critical incident management procedure

2. Involvement of occupational health $(\mathrm{OH})$ where appropriate

3. Information and support from $\mathrm{HR}, \mathrm{OH}$ and senior management

4. Training.

Chapter 17 also contains some useful appendices, with templates for stressrelated illness and absence procedures, individual risk assessment, critical incident management procedure, and one-day workshop for managers.

Chapter 18 then discusses the typical signs and symptoms of stress that managers may see in their teams, and also the sorts of organizational signs that stress levels are going up overall. If they take the time to listen and be aware of their team's stress levels, most managers will see signs of stress. However, approaching a stressed employee to talk about performance or health can be nerve-racking and most managers welcome help in this area. Chapter 19 covers in depth the issue of having conversations with employees about their stress levels. The tips, ideas, and skills discussed should ease manager's nervousness; they also have application in general management.

Finally, Chapter 20 summarizes the key themes about how managers can grasp the nettle of team stress levels, rather than letting fear, ignorance, or lack of procedure exacerbate pressure and ill health. 